\title{
Metaphyseal growth arrest lines in psychosocial short stature
}

\author{
V V Khadilkar, F L Frazer, D H Skuse, R Stanhope
}

\begin{abstract}
Metaphyseal growth arrest lines are seen in children who experience significant physical stress such as infection or malnutrition over a sufficient period of time. These lines have not been reported previously in children with psychosocial short stature (PSS). Two boys and a girl with PSS with metaphyseal growth arrest lines on skeletal radiographs at the time of maximal stress in their homes are described. All three had reversible growth hormone insufficiency during admission, which is pathognomic for PSS. Multiple growth arrest lines in the distal end of the radius or vertebrae should alert clinicians to an alternative diagnosis in a child with growth hormone insufficiency. This may provide a clue to the diagnosis of occult PSS.
\end{abstract}

(Arch Dis Child 1998;79:260-262)

Keywords: psychosocial short stature; linear growth; growth arrest lines

Opaque transverse lines in the metaphyses of growing long bones (Harris's lines) are found in children with a variety of clinical disorders. ${ }^{1}$ Marginal lines of increased density in the round and flat bones, such as the vertebrae, develop under the same circumstances. Such lines have even been observed in Egyptian mummies. ${ }^{2}$ They have been reported in a variety of childhood conditions such as malnutrition, ${ }^{3}$ infections, ${ }^{3}$ hypothyroidism, ${ }^{4}$ hypoparathyroidism, ${ }^{5}$ Cushing's syndrome ${ }^{6}$ juvenile chronic arthritis, ${ }^{7}$ and during chemotherapy for malignancies in childhood. ${ }^{8-10}$ They have also been reported with immobilisation of extremities during orthopaedic procedures. ${ }^{1}$ These lines were described in the original observations of growth failure in maternal deprivation but their significance was not appreciated. ${ }^{11}$ They are contemporaneous with growth arrest and tend to persist for several years. They have not been reported in psychosocial short stature (PSS).

PSS is a condition where growth failure without organic cause is associated with behavioural disturbance and psychosocial stress. Many of the children with PSS have specific appetite disturbances, particularly hyperphagia, stealing food from home and from school, hoarding food, gorging and vomiting, excessive drinking, pica, eating discarded food and from bins, and searching for food at night. ${ }^{12}$ Recovery of pituitary function in PSS is usually seen within 16 days of a change in environment. ${ }^{13}$ Growth hormone insufficiency or panhypopituitarism has been reversed in children with hyperphagic PSS when they are removed from their stressful home environment. $^{12}$

We report three cases of PSS with bilateral metaphyseal growth arrest lines at multiple sites on skeletal surveys at the time of maximal stress in their homes. Skeletal surveys were performed at the time of admission to the endocrinology ward at Great Ormond Street Hospital, London, UK to exclude nonaccidental injury. No radiological evidence was found for non-accidental injury. None of the children had a history of malnutrition, supported by body mass index data (table 1). All other biochemical and endocrine investigations were normal. We showed reversible growth hormone insufficiency in all three children during their three week admission, pathognomonic of the condition (table 2).

\section{Case 1}

This child was born at 29 weeks' gestation with a birth weight of $1350 \mathrm{~g}$. He was the fifth child of separated parents. At 4 years old he was referred for assessment of growth failure. At this time he was registered with the local child protection services because of suspected physical abuse and maternal neglect. At initial assessment he was noted to have developmental delay, moderate hearing loss, and behavioural difficulties including encopresis. He had a history of hyperphagia and stealing food from the refrigerator at home, and was described as "always hungry".

During admission we found reversible growth hormone insufficiency, which supported the diagnosis of PSS. Skeletal survey showed multiple metaphyseal growth arrest lines at the ends of the radii, ulnae, tibiae, and

Table 1 Auxological data before admission in three children with psychosocial short stature

\begin{tabular}{lllll}
\hline Case & Age (years) & $\begin{array}{l}\text { Height } \\
\text { SDS }\end{array}$ & $\begin{array}{l}\text { Height velocity } \\
\text { SDS }\end{array}$ & $\begin{array}{l}\text { BMI } \\
\text { SDS }\end{array}$ \\
\hline 1 & 4.3 & -3.3 & -5.3 & +2.5 \\
2 & 5.4 & -4.2 & -1.3 & +0.5 \\
3 & 7.7 & -2.9 & -0.3 & +0.8
\end{tabular}

SDS, standard deviation score.

Table 2 Peak growth hormone concentrations achieved following glucagon stimulation tests in three children with psychosocial short stature

\begin{tabular}{lcc}
\hline & \multicolumn{2}{c}{ Growth hormone concentration $(\mathrm{mU} / \mathrm{l})$} \\
\cline { 2 - 3 } Case & Initial & $\begin{array}{l}\text { At the end of } \\
\text { 3 week admission }\end{array}$ \\
\hline 1 & 3.5 & 107.0 \\
2 & 8.6 & 30.6 \\
3 & 10.8 & 23.0 \\
\hline
\end{tabular}




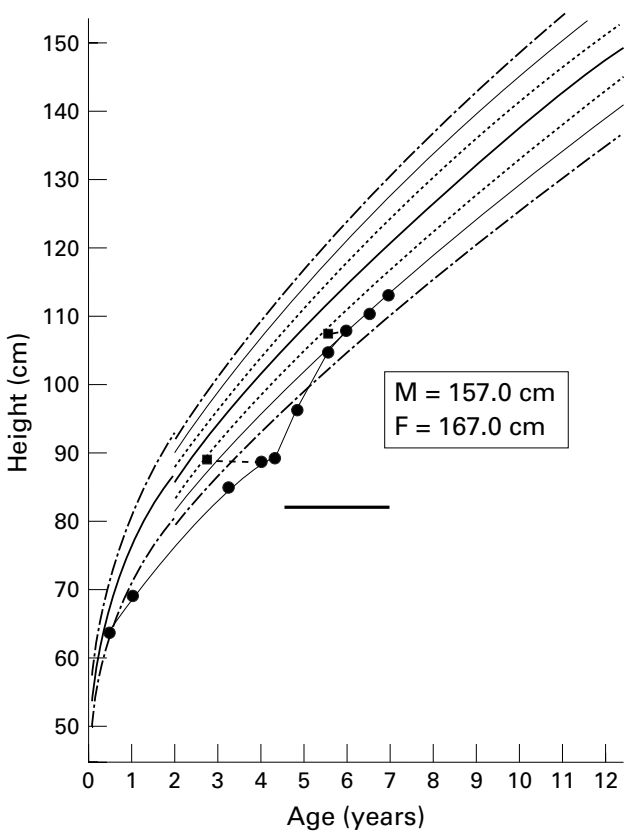

Figure 1 Growth data from case 1. The horizontal bar represents the time in foster care; the squares represent bone age. Maternal $(M)$ and paternal $(F)$ heights are shown.

fibulae. He was discharged into foster care resulting in notable improvement in growth velocity that has been maintained (fig 1 ).

\section{Case 2}

This girl was born at 41 weeks' gestation with a birth weight of $3936 \mathrm{~g}$. Her younger sibling had died of suspected sudden infant death syndrome. Our patient had a history of physical abuse, developmental delay, and suspected PSS with hyperphagia. She stole food and was described as constantly hungry. We found reversible growth hormone insufficiency during admission. A skeletal survey showed five growth arrest lines at the end of all the long bones (fig 2) as well as the characteristic "bone within bone" appearance within vertebrae. At 5.5 years old she was placed in foster care with improvement in growth velocity. At 6.2 years old she was returned to her biological parents and her growth velocity decreased. At 6.8 years old she was returned to foster care with contemporaneous catch up growth and resolution of hyperphagia; at 9 years old she was adopted.

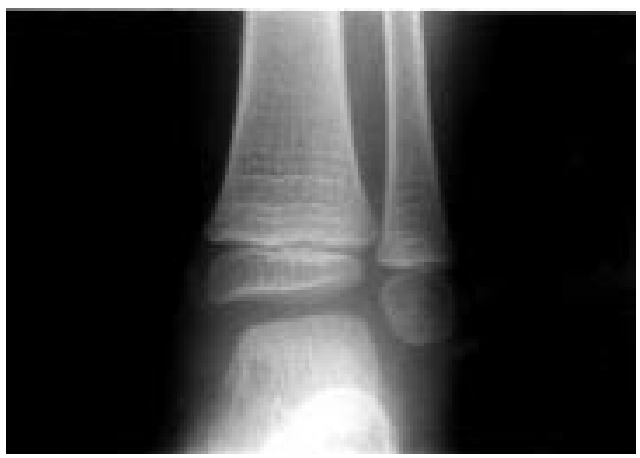

Figure 2 Radiograph of the distal tibia and fibula from case 2 with psychosocial short stature. Multiple growth arrest lines are seen in the metaphyses.

\section{Case 3}

This patient was the first born child of parents with severe mental illness. He was delivered full term with birth weight $3360 \mathrm{~g}$. He was adopted at 1 year. In his adoptive family he was the youngest child with two older sisters. $\mathrm{He}$ suffered emotional abuse and possible physical abuse. At 8 years old he was referred because of short stature. Tests showed growth hormone insufficiency and he was started on growth hormone treatment. He had a suboptimal response with failure to increase height velocity to expected levels. His adoptive parents and school teachers gave a history of disruptive and aggressive behaviour. He had a normal eating pattern. There was no history of encopresis or abnormal sleep behaviour. At 11.7 years old he was admitted to hospital for endocrine reassessment. Skeletal survey showed multiple metaphyseal growth arrest lines at the ends of each radius. Growth hormone treatment was continued at a dosage of $20 \mathrm{U} / \mathrm{m}^{2} /$ week. Growth velocity improved at 13 years of age after his home environment improved following separation of his adoptive parents and intervention of social services.

\section{Discussion}

The diagnosis of PSS is based on reversible growth failure and pituitary dysfunction before and after the removal of a child from an adverse environment. All three children had such an environment, growth failure, reversible growth hormone insufficiency, and multiple metaphyseal growth arrest lines.

Our observation of metaphyseal growth arrest lines in PSS has not previously been reported. Metaphyseal growth arrest lines are seen in children with a variety of diseases but the exact mechanism remains uncertain. They appear to form whenever there is sufficient stress over a long enough time period, such as starvation or severe, chronic illness. ${ }^{1}$ It is assumed that acute injury and illness are a threat to survival similar to malnutrition, and that mechanisms concerned with production and modification of growth stimulating factors at the growth plate of bones are inhibited. ${ }^{14}$

The children we studied clearly had psychological stress from longstanding adverse environments before it was suspected and social services alerted. At the time of the first pituitary function tests these children had growth hormone insufficiency, which was reversed after the change of environment. It is significant that metaphyseal growth arrest lines are not seen in children with growth hormone insufficiency and panhypopituitarism despite growth failure. Animal models suggest that an initial period of growth suppression and subsequent recovery are necessary for these lines to occur. ${ }^{13}$ They seem to develop in children under the same circumstances. When the process is repetitive many lines may be produced. The mechanism in PSS is also related to varying intensities of abuse and stress spread over time, so that periods of stress and recovery are likely to alternate.

The clinical assessment of children with growth failure usually involves a wrist $x$ ray to 
estimate epiphyseal maturation; such children may also have a skeletal survey to exclude skeletal dysplasia or non-accidental injury. Multiple growth arrest lines in the distal end of the radius or vertebrae should alert the clinician to an alternative diagnosis in a child with growth hormone insufficiency. This may provide a clue to the diagnosis of occult PSS. ${ }^{15}$

VVK was supported by Eli Lilly UK. FLF was supported by The Child Growth Foundation. We are grateful to Serono UK for secretarial support.

1 Silverman FN. Variants due to diseases of bone. In: Silverman FN, Kuhn JP, eds. Caffey's pediatric x-ray diagnosis: an integrated imaging approach. 9th ed. Philadelphia: Mosby, 1994:1521-7.

2 Autopsy of an Egyptian mummy. Can Med Assoc $\mathcal{f}$ 1977;117:461-76.

3 Park EA. The imprinting of nutritional disturbances on growing bone. Pediatrics 1964;33:815-62.

4 Boyages SC, Halpern JP, Maberly GF, et al. A comparative study of neurological and myxedematous endemic cretinism in western China. $\mathcal{F}$ Clin Endocrinol Metab 1988;67: ism in west
5 Rosen RA, Deshmukh SM. Growth arrest recovery lines in hypoparathyroidism. Radiology 1985;155:61-2.

6 Bessler W. Vertebral growth arrest lines after Cushing's syndrome. A case report. Diagnostic Imaging 1982;51:311-15.

7 Fiszman P, Ansell BM, Renton P. Radiological assessment of knees in juvenile chronic arthritis (juvenile rheumatoid arthritis). Scand F Rheumatol 1981;10:145-52.

8 Schwartz AM, Leonidas JC. Methotrexate osteopathy. Skeltal Radiol 1984;11:13-16.

9 Meister B, Gassner I, Streif W, Dengg K, Fink FM. Methotrexate osteopathy in infants with tumors of the cen-
tral nervous system. Med Pediatr Oncol 1994;23:493-6.

10 Bar On E, Beckwith JB, Odom LF, Eilert RE. Effect of chemotherapy on human growth plate. $\mathcal{f}$ Pediatr Orthop 1993;13:220-4.

11 Patton RG, Gardner LI. Growth failure in maternal deprivation. Springfield: Charles C Thomas, 1967:25-51.

12 Skuse D, Albanese A, Stanhope R, Gilmour J, Voss L. A new stress-related syndrome of growth failure and hyperphagia in children, associated with reversibility of growthhormone insufficiency. Lancet 1996;348:353-8.

13 Albanese A, Hamill G, Jones J, Skuse D, Matthews DR, Stanhope R. Reversibility of physiological growh hormone secretion in children with psychosocial dwarfism. Clin Endocrinol 1994;40:687-92.

14 Siffert RS, Katz JF. Growth recovery zones. F Pediatr Orthop 1983;3:196-201.

15 Gohlke BC, Khadilkar VV, Skuse D, Stanhope R. Recognition of children with psychosocial short stature: a spectrum of presentation. $\mathcal{F}$ Pediatr Endocrinol Metab. [In press.] 